\title{
Assessment of Perceived Stress among Nurses of Tertiary Care Hospital during COVID Pandemic - A Cross-Sectional Study
}

\author{
Anwar UL Huda ${ }^{1 *}$, Mohammad Yasir ${ }^{1}$, Swaid Raza Saulat ${ }^{1}$, Mohammad waleed Alshaqha ${ }^{1}$ \\ ${ }^{1}$ Department of Anesthesia, Security Forces Hospital, Riyadh, Kingdom of Saudi Arabia
}

DOI: $10.36348 /$ sjnhc.2021.v04i03.001

| Received: 14.02.2021 | Accepted: 11.03.2021 | Published: 15.03.2021

*Corresponding author: Anwar Ul Huda

\section{Abstract}

Background: Nurses are the frontline healthcare workers and during the current pandemic COVID-19, they are at increased risk. Considering their work patterns and the pressure of the work, they experience stress. There is very little data available regarding the incidence of stress among nurses during this pandemic. Methods: This was a cross-sectional study which was done at Security Forces Hospital, Riyadh, Kingdom of Saudi Arabia. The objective of this study was to examine the presence of stress among nurses working in a tertiary care hospital. We calculated the sample size as 57 . We used the Perceived stress scale (PSS) in our study. We gave the questionnaire comprising PSS questions to nurses from different wards. We calculated the mean, standard deviation, frequency count, and percentages for the perceived stress. Results: The mean PSS-10 score was 20.8 (SD: 4.61) with a range between 11 and 29. Two (3.3\%) nurses had low stress and $52(86.7 \%)$ nurses had moderate stress while $6(10 \%)$ nurses had high stress. Conclusion: The majority of nurses in our study experienced a moderate level of stress during this COVID-19 pandemic.

Keywords: Stress, COVID-19, nurses, pandemic.

Copyright (C) 2021 The Author(s): This is an open-access article distributed under the terms of the Creative Commons Attribution 4.0 International License (CC BY-NC 4.0) which permits unrestricted use, distribution, and reproduction in any medium for non-commercial use provided the original author and source are credited.

\section{INTRODUCTION}

Healthcare professionals (HCP) are known to be more susceptible to psychological distress compared to other members of society [1]. In one study in Jordan, poor psychosocial work environment, poor social support, and dealing with uncooperative patients were found to be associated with burnout among mental health nurses [1]. Alharbi et al., [2] showed that the mean score of PSS10 in ICU nurses of one of the government hospitals in Saudia Arabia was 17.71. Most of the nurses reported a moderate stress level while only a few experienced a low stress level.

As the world is experiencing a massive burden of the COVID-19 pandemic, WHO reported a total of 52,177,708 confirmed COVID-19 cases and 1,286,063 total deaths [3]. Nurses are on the front line expressing their great commitment and passion despite risking their life [4]. But this increased physical and psychosocial pressure is believed to be associated with further significant psychological disturbances on healthcare professionals (HCP) [2]. Data about stress among nurses during this COVID-19 pandemic is scarce and we could not find any study in Saudi Arabia. Therefore the objective of this study is to examine the presence of stress among nurses working in tertiary care hospitals of Saudi Arabia.

\section{MATERIAL AND METHODS}

This was a cross-sectional study conducted in Security Forces Hospital, Riyadh, Kingdom of Saudi Arabia during September- October 2020. We included the nurses from different wards of our hospital including medical, surgical, anesthesia, ER, and critical care units. The sample size was calculated using the online calculator [5] and came out as 57. We used convenience sampling to select study respondents. Ethical approval was taken from the institutional ethical review committee. The nurses were informed about the purpose and significance of this study. We used The Perceived Stress Scale (PSS) for assessing the stress levels among nurses. PSS is the most widely used psychological instrument for measuring the perception of stress. It is a measure of the degree to which situations in one's life are appraised as stressful. Items are designed to tap how unpredictable, uncontrollable, and overloaded respondents find their lives. Each item was answered by the trainees on a five-point scale ranging from never $(0)$ to very often $[4,6]$. The scale has been used in Saudi healthcare workers in one previous study by Alharbi et al., [2]. 
Anwar UL Huda et al., Saudi J Nurs Health Care, Mar, 2021; 4(3): 45-47

Nurses were requested to fill the questionnaire either online on survey monkey or in paper form. All data were entered and analyzed using SPSS version 26. We calculate Mean, standard deviation, frequency count, and percentages for the perceived stress.

\section{RESULTS}

A total of 60 nurses were included in this study. Five nurses filled the questionnaire using the survey monkey link while 55 nurses filled the paper questionnaire. The Mean PSS-10 score was 20.8 (SD: 4.61) with a range between 11 and 29. Two (3.3\%) nurses had low stress and $52(86.7 \%)$ nurses had moderate stress while $6(10 \%)$ nurses had high stress as shown in graph 1.

\section{DISCUSSION}

Nurses are the key players and playing a major role in the prevention of infection, its isolation, containment, and public health care. With the current situation of COVID-19, the psychological aspect of working in healthcare has got worsened. Scientific literature from previous epidemics has shown significant individual and social psychosocial impact following epidemics and outbreaks in the past [7, 8]. During this COVID-19 pandemic, the world is going through a shutdown or slow down in daily activities but on the other hand, healthcare professionals need to continue their working schedules [9]. Additionally, because of increasing healthcare demand, they work longer shifts often with limited resources and with the need to wear personal protective equipment (PPE) resulting in physical discomfort as well. Also, they are at risk of getting infected and the risk of spreading the virus to their family and friends. This fear makes them isolate themselves from family and friends resulting in various levels of psychological pressure and dysphoric states like stress, irritability, fatigue, and despair [10].

In 2003, during the outbreak of SARS (severe acute respiratory syndrome), $18-57 \%$ of healthcare professionals experienced serious emotional and psychiatric disturbances. During the outbreak of MERS (Middle East respiratory syndrome) in 2015, dysphoria and stress were reported among HCPs [11]. During this COVID pandemic, a large survey of HCPs in China [12] reported the prevalence rate of traumatic stress as $73.4 \%$, depression as $50.7 \%$, and generalized anxiety as $44.7 \%$ while our study reported an alarmingly high prevalence of stress as $96.7 \%$ among nurses. One previous study in Saudia Arabia [2] reported the mean PSS-10 score of nurses as 17.71 $(\mathrm{SD}=3.76)$ which is again lower than reported in our study as 20.8. The majority of the nurses in that study (2) reported moderate stress level which is consistent with our study. Another study in France [13] reported mean PSS-10 as 14.4 which was lower than reported in our study. Although, a survey in Jordan [14] reported a higher mean PSS-10 score as 22.62 and another study
[15] in the Midwest region of the United States reported a mean perceived stress score of 21.76. There are some limitations in our study. Firstly, this is a single centre study. We did not include the level and ward location of nurses in our study.

\section{CONCLUSION}

The majority of nurses in our study experienced a moderate level of stress during this COVID pandemic. We, therefore, recommend for provision of better psychosocial support for nurses during the pandemic.

\section{Acknowledgment: None}

\section{REFERENCES}

1. Hamaideh, S. H. (2011). Burnout, social support, and job satisfaction among Jordanian mental health nurses. Issues in Mental Health Nursing, 32(4), 234-242.

2. Alharbi, H., \& Alshehry, A. (2019). Perceived stress and coping strategies among ICU nurses in government tertiary hospitals in Saudi Arabia: a cross-sectional study. Annals of Saudi medicine, 39(1), 48-55.

3. World Health Organization. (2020, March 11). WHO characterizes COVID-19 as a pandemic. Retrieve from https://www.who.int/emergencies/diseases/novelcoronavirus-2019/events-as-they-happen

4. Mo, Y., Deng, L., Zhang, L., Lang, Q., Liao, C., Wang, N., ... \& Huang, H. (2020). Work stress among Chinese nurses to support Wuhan in fighting against COVID- 19 epidemic. Journal of nursing management, 28(5), 1002-1009.

5. Dhand, N. K., \& Khatkar, M. S. (2014). Statulator: An online statistical calculator. Sample Size Calculator for Estimating a Single Mean. Accessed 16 June 2020 at http://statulator.com/SampleSize/ss1M.html

6. Cohen, S., \& Williamson, G. (1988). Perceived Stress in a Probability Sample of the United States. Spacapan, S. and Oskamp, S. (Eds.) The Social Psychology of Health. Newbury Park, CA: Sage.

7. Li, Z., Ge, J., Yang, M., Feng, J., Qiao, M., Jiang, R., ... \& Yang, C. (2020). Vicarious traumatization in the general public, members, and non-members of medical teams aiding in COVID-19 control. Brain, behavior, and immunity, 88, 916919.

8. Ornell, F., Schuch, J. B., Sordi, A. O., \& Kessler, F. H. P. (2020). "Pandemic fear" and COVID-19: mental health burden and strategies. Brazilian Journal of Psychiatry, 42(3), 232-235.

9. Wilder-Smith, A., \& Freedman, D. O. (2020). Isolation, quarantine, social distancing and community containment: pivotal role for old-style public health measures in the novel coronavirus 
Anwar UL Huda et al., Saudi J Nurs Health Care, Mar, 2021; 4(3): 45-47

(2019-nCoV) outbreak. Journal of travel medicine, 27(2), taaa020.

10. Huang, J. Z., Han, M. F., Luo, T. D., Ren, A. K., $\&$ Zhou, X. P. (2020). Mental health survey of 230 medical staff in a tertiary infectious disease hospital for COVID-19. Zhonghua lao dong wei sheng zhi ye bing za zhi= Zhonghua laodong weisheng zhiyebing zazhi $=$ Chinese journal of industrial hygiene and occupational diseases, 38, E001-E001.

11. Lee, S. M., Kang, W. S., Cho, A. R., Kim, T., \& Park, J. K. (2018). Psychological impact of the 2015 MERS outbreak on hospital workers and quarantined hemodialysis patients. Comprehensive psychiatry, 87, 123-127.

12. Liu, S., Yang, L., Zhang, C., Xiang, Y. T., Liu, Z., Hu, S., \& Zhang, B. (2020). Online mental health services in China during the COVID-19 outbreak. The Lancet Psychiatry, 7(4), e17-e18.

13. Jones, G., Hocine, M., Salomon, J., Dab, W., \&

Temime, L. (2015). Demographic and occupational predictors of stress and fatigue in French intensive-care registered nurses and nurses' aides: a cross-sectional study. International journal of nursing studies, 52(1), 250-259.

14. Masa'Deh, R., Masadeh, O., Jarrah, S., AlAzzam, M., \& Alhalaiqa, F. (2020). Effect of aggression management training on perceived stress levels of nurses working in mental health care settings in Jordan. Journal of Psychosocial Nursing and Mental Health Services, 58(10), 32-38.

15. Oyeleye, O., Hanson, P., O’Connor, N., \& Dunn, D. (2013). Relationship of workplace incivility, stress, and burnout on nurses' turnover intentions and psychological empowerment. JONA: The Journal of Nursing Administration, 43(10), 536542. 